\title{
Effects of Different Dietary Vitamin Combinations on the Egg Quality and Vitamin deposition in the Whole Egg of Laying Hens
}

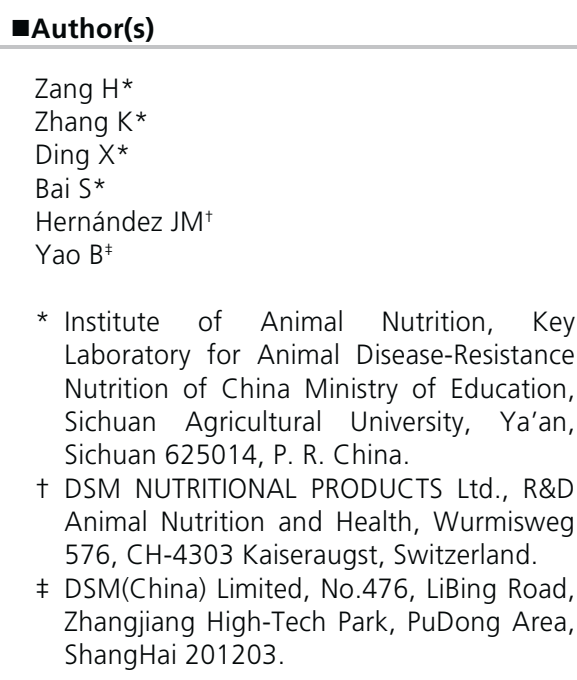

Mail Address

K Zhang

Institute of Animal Nutrition

Key Laboratory for Animal Disease-Resistance Nutrition of China Ministry of Education

Sichuan Agricultural University

Ya'an, Sichuan 625014, P. R. China

Tel: +86-13981605686

Fax: $+86-835-2885630$

E-mail: zkeying@yahoo.com

\section{-Keywords}

Egg quality, Hy. $D^{\circledR}$, laying hen, $\mathrm{OVN}^{\circledR}{ }^{\circledR}$, vitamin deposition.

\begin{abstract}
The experiment was conducted to evaluate the effects of different dietary vitamin combinations on the egg quality and vitamin concentrations in the eggs of commercial laying hens. A total of 1,800 25-week-old Lohman pink-shell hens were randomly assigned to four dietary vitamin treatments as follows: NRC(1994) level, NRC (1994) level with Hy.D ${ }^{\circledR}$ (25-hydroxy-cholecalciferol), Local level (current average industry level in China) and OVN ${ }^{\circledR}$ level (optimum vitamin nutrition level), with 10 replicates per treatment and 45 layers per replicate. Hens were housed in commercial laying cages with three birds per cage and given ad libitum access to feed. Results showed the hens that received the fortified vitamin levels in the $\mathrm{OVN}^{\circledR}$ treatment had a significantly $(p<0.05)$ lower number of cracked $(.47 \%)$ and dirty eggs $(.27 \%)$, and increased egg deposition of vitamin $B_{12}$, folic acid, vitamin $A$, vitamin $D, 25-O H-D_{3}$, vitamin $E$, vitamin $B_{1}$, biotin and pantothenate $(p<0.05)$. Treatments had no significant effect on egg-shape index, egg specific gravity, Haugh units and eggshell thickness. Hens fed the NRC-Hy.D ${ }^{\circledR}$ combination also experienced a significant decrease in cracked and dirty eggs (.70\% and $.44 \%$, respectively) and an increased deposition of $25-\mathrm{OH}-\mathrm{D}_{3}$ in comparison with the NRC treatment. Results of the present study suggest that that the Local treatment was able to improve egg quality parameters of laying hens, but resulted in more cracked and dirty eggs. $O V N^{\circledR}$ reduced the number of cracked eggs and dirty eggs, and improved the deposition of several vitamins in eggs. With the addition of $\mathrm{Hy} . \mathrm{D}^{\circledR}$, eggshell strength and $25-\mathrm{OH}-\mathrm{D}_{3}$ deposition in eggs were also improved, and cracked and dirty egg rates declined.
\end{abstract}

\section{INTRODUCTION}

Vitamins are essential nutrients found in foods. While their requirements are small, they perform specific and vital functions essential for health maintenance. Vitamin deficiencies may lead to a series of diseases in humans. Vitamin A deficiency is the most frequent cause of blindness among pre-school children (Underwood, 1998), abortion of pregnant women and newborn mortality (Radhika et al., 2002) in developing countries. Vitamin D deficiency is a common problem during the winter in Europe, because of the restricted ultraviolet light exposure (Scharla, 1998). A less severe vitamin D deficiency can result in postmenopausal osteoporosis (Lips et al., 2001) and may also increase the risk of initiation and progression of prostate cancer (Tuohimaa et al., 2001). Folate deficiency can result in an increase in plasma homocysteine concentrations, which is linked to an increased risk for cardiovascular disease (Boushey et al., 1995; Refsum et al., 1998), Alzheimer's disease (Morris, 2003), and osteoporosis (Mclean et al., 2004). There is an increased awareness of the importance of this 
B-vitamin due to the fact that supplemental folic acid has been shown to reduce a woman's risk for having a baby with a neural tube defect (Czeizel \& Dudas, 1992; Scott, 1999). Therefore considerable attention has been given to the development of strategies to increase human vitamin intake.

Poultry products contribute significantly to the vitamin intake of consumers. Eggs are one of the most common daily foods, and naturally contain most of the recognized vitamins (vitamin $A$, vitamin $D$, vitamin $E$ and B-vitamins), except for vitamin C. Improvements in egg nutritional value may have direct positive implications for daily nutrient intake and consequently for human health (Nys \& Sauveur, 2004). Vitamin-enriched eggs are attractive as a vehicle that can provide consumers with compounds that may be beneficial to health or to over come nutritional imbalances. Like many other nutrients, vitamin levels incorporated into feed directly influence the deposition of vitamins in eggs (Naber \& Squires, 1993). Vitamin concentration is influenced by genetics, egg production rate and, similarly to fatty acids, it varies with the composition of the hens' diet (Naber, 1993; Leeson \& Caston, 2003). With a moderate enrichment of vitamins in accordance with the recommendations for fortification of foods, eggs could play an important role as a functional food. Numerous relevant data related to egg vitamin enrichment through nutrition strategies are now presented, with special attention paid to fat-soluble vitamins $E, A, D$, but also to vitamin $B_{12}$ and folic acid. Naber (1993) summarized his findings, classifying the transfer efficiency of vitamins from the diet of hens to eggs, which was very high for vitamin $A$; high for riboflavin, pantothenic acid, biotin, and vitamin $B_{12}$; medium for vitamin $D_{3}$ and $E_{\text {; }}$ and low for vitamin $K$, thiamine and folacin; however, the combined effects of vitamin premix on vitamin deposition in eggs are rarely reported. Therefore, the aim of the present study was to investigate the possibility of enhancing vitamin accumulation in eggs through their supplementation in commercial laying hen diets and to determine the effects of these vitamins on egg quality parameters.

\section{MATERIALS AND METHOD}

This animal experiment was conducted in accordance with guidelines approved by Animal Health and Care Committee of Sichuan Agricultural University and was performed in accordance with recommendations of the China Council on Animal Care as specified in the Guide to the Care and Use of Experimental Animals.

\section{Animals and Housing}

A total of 1,800 25-week-old Lohmanpink-shell commercial laying hens were randomly assigned to four dietary treatments, with 10 replicates per treatment and 45 layers per replicate. All hens were housed in commercial laying cages with three birds per cage $(40 \times 35 \times 40 \mathrm{~cm})$ according to a randomized complete block design at the Animal Nutrition Research Centre of Sichuan Agricultural University for a 39-wk trial. Hens received $16 \mathrm{~h} / \mathrm{d}$ of manipulated lighting and ventilation at a natural ambient temperature. Feed and water were provided ad libitum throughout the experiment.

\section{Experimental design and diets}

The single factorial design consisted of four vitamin levels (as shown in Table 1): NRC (1994) level, NRC (1994) level with Hy.D ${ }^{\circledR}$ (25-hydroxy-cholecalciferol), Local level (the current average industry level in China) and $O \mathrm{ON}^{\circledR}$ level (optimum vitamin nutrition level), the supplemental level of each of them in basal diet was $400 \mathrm{mg} / \mathrm{kg}$. The basal diet was a corn-soybean mealrapeseed meal layer diet formulated according to the recommendations of NRC (1994) (Table 2). Vitamins were supplied by DSM (DSM China Ltd Corp, Shanghai, P. R. China).

Table 1 - Composition and content of the experimental vitamin premixes added to the layer diet.

\begin{tabular}{|c|c|c|c|c|}
\hline \multirow{2}{*}{ Ingredients (- / kg diet) } & \multicolumn{4}{|c|}{ Vitamin content } \\
\hline & Local & $\mathrm{OVN}^{\circledR}$ & $\mathrm{NRC}+\mathrm{Hy} . \mathrm{D}^{\circledR}$ & NRC \\
\hline Vitamin A, IU & 8520 & 12500 & 3000 & 3000 \\
\hline Vitamin $D_{3}, I U$ & 2400 & 2500 & 300 & 300 \\
\hline $25-\mathrm{OH}-\mathrm{D}_{3}, \mathrm{mg}$ & - & 0.035 & 0.035 & - \\
\hline Vitamin E, IU & 18.50 & 30.00 & 5.00 & 5.00 \\
\hline Vitamin $\mathrm{K}_{3}, \mathrm{mg}$ & 1.43 & 2.00 & 0.50 & 0.50 \\
\hline Vitamin $B_{1}, \mathrm{mg}$ & - & 1.50 & 0.70 & 0.70 \\
\hline Vitamin $\mathrm{B}_{2}, \mathrm{mg}$ & 3.30 & 6.30 & 2.50 & 2.50 \\
\hline Vitamin $\mathrm{B}_{6}, \mathrm{mg}$ & 0.715 & 3.80 & 2.50 & 2.50 \\
\hline Vitamin $B_{12}, \mathrm{mg}$ & - & 0.0188 & 0.004 & 0.004 \\
\hline Niacin, mg & 24.50 & 40.00 & 10.00 & 10.00 \\
\hline Pantothenic acid, mg & 8.90 & 11.30 & 2.00 & 2.00 \\
\hline Folic acid, mg & 0.50 & 1.00 & 0.25 & 0.25 \\
\hline Biotin, mg & - & 0.125 & 0.10 & 0.10 \\
\hline Vitamin C, mg & - & 100.00 & - & - \\
\hline
\end{tabular}

\section{Data collection}

The number of dirty and cracked eggs were recorded daily by replicate and determined on the basis of each replicate weekly. Every four weeks of the trial, 10 eggs per replicate were randomly collected for the measurement of egg-shape index (ESI), egg specific gravity (ESG), eggshell strength (ESS), eggshell 
thickness (EST) and Haugh unit (HU). Egg specific gravity was determined by using the saline flotation method as described by Hempe et al. (1988). Haugh unit was calculated using the formula of Eisen et al. (1962) based on the height of albumen determined by a micrometer and egg weight. The eggshell strength and thickness were determined using the eggshell strength meter and eggshell thickness gauge (Fujihira Corp., Tokyo, Japan) respectively. After the last eggshell quality measurements were taken, the entire contents of eggs were collected and homogenized on the basis of each replicate. Samples were frozen and then freeze-dried to constant weight. Subsamples were reground and then allowed to equilibrate with ambient moisture at room temperature. Samples were sent to Analytical Research Center of DSM Nutritional Products Ltd (Switzerland) to determine the content for all vitamins using HPLC.

Table 2 - Ingredients and nutrient composition of the basal diet fed to laying hens.

\begin{tabular}{|c|c|}
\hline Ingredient and composition & Amount (\%) \\
\hline Corn & 66.08 \\
\hline Soybean meal & 20.86 \\
\hline Rapeseed meal & 3.00 \\
\hline Calcium Carbonate & 7.82 \\
\hline $\mathrm{CaHPO} 4$ & 1.13 \\
\hline Salt & 0.37 \\
\hline Choline Chloride & 0.10 \\
\hline DL-Methionine & 0.10 \\
\hline Vitamin premix ${ }^{1}$ & 0.04 \\
\hline Mineral premix ${ }^{2}$ & 0.50 \\
\hline \multicolumn{2}{|l|}{ Calculated nutrient composition } \\
\hline $\mathrm{ME}, \mathrm{MJ} / \mathrm{kg}$ & 11.29 \\
\hline Crude protein, $\%$ & 16.00 \\
\hline Calcium, \% & 3.50 \\
\hline Non-phytate phosphorus, $\%$ & 0.32 \\
\hline Methionine, \% & 0.35 \\
\hline Lysine, \% & 0.75 \\
\hline Methionine + Cystine, \% & 0.65 \\
\hline \multicolumn{2}{|c|}{$\begin{array}{l}1 \text { - Vitamin premix (supplied per kilogram of diet) as shown in Table 1. } 2 \\
\text { - Mineral premix (supplied per kilogram of diet): Iron }\left(\mathrm{FeSO}_{4} 7 \mathrm{H}_{2} \mathrm{O}\right), 60 \mathrm{mg} ; \\
\left.\text { Copper }\left(\mathrm{CuSO}_{4} 5 \mathrm{H}_{2} \mathrm{O}\right) \text {, 8.0mg; Manganese ( } \mathrm{MnSO}_{4} \mathrm{H}_{2} \mathrm{O}\right), 60 \mathrm{mg} ; \text { Zinc } \\
\left(\mathrm{ZnSO}_{4} 7 \mathrm{H}_{2} \mathrm{O}\right), 80 \mathrm{mg} \text {; lodine }(\mathrm{KI}), 0.35 \mathrm{mg} \text {; Selenium }\left(\mathrm{Na}_{2} \mathrm{SeO}_{3}\right), 0.3 \mathrm{mg} \text {. }\end{array}$} \\
\hline
\end{tabular}

\section{Statistical analyses}

Data were analyzed by one-way analysis of variance using ANOVA procedure of SPSS (SPSS11.0, 2001) and significant differences among treatment means were compared using the least significant difference test. Statements of statistical significance were based on a probability of $(p<0.05)$.

\section{RESULTS}

\section{Egg quality parameters, cracked egg and dirty egg of laying hens}

As shown in Table 3, the effects of different dietary vitamin levels exhibited did not result in significant differences in the egg quality parameters measured, such as ESI, ESG, HU and EST ( $p>0.05$ ); however, ESS in the Local group $\left(4.33 \mathrm{~kg} / \mathrm{cm}^{2}\right)$ was significantly higher than the other treatments $\left(4.06,4.07,3.92 \mathrm{~kg} / \mathrm{cm}^{2}\right.$ for OVN ${ }^{\circledR}, N R C$ with Hy. $D^{\circledR}$, and NRC level, respectively) $(p<0.05)$. CEP and DEP in the vitamin fortified group $\left(O V N^{\circledR}\right)$ was significantly reduced $(p<0.05)$ as compared to other treatments. As for NRC with Hy. ${ }^{\circledR}$, with the addition of Hy. ${ }^{\circledR}$ in the diet, CEP and DEP significantly declined. Furthermore, ESS was significantly improved $(p<0.05)$, as compared with NRC or Local level diet.

\section{Vitamin concentration in whole eggs}

Results of vitamin concentration in whole eggs were presented in Table 4. Concentrations of vitamin $B_{12}$, vitamin $A$, vitamin $E$, vitamin $B_{1}$ and pantothenate in whole egg in the $\mathrm{OVN}^{\circledR}$ group were all significantly higher in comparison with Local, NRC with Hy.D ${ }^{\circledR}$ and NRC groups $(p<0.05)$. Folic acid and vitamin $D$ concentrations for $O \mathrm{OVN}^{\circledR}$ and Local levels were both significantly higher than NRC with $H y . D^{\circledR}$ and NRC levels $(p<0.05)$, while no significant difference was observed between them $(p>0.05)$. Vitamin $B_{2}$ concentrations were similar among the four dietary treatments with no significant difference $(p>0.05)$. $25-\mathrm{OH}-\mathrm{D}_{3}$ concentration for the $\mathrm{OVN}^{\circledR}$ level was

Table 3 - Effects of dietary treatment on ESI, ESG, ESS, HU, EST, CEP and DEP of laying hens.

\begin{tabular}{|c|c|c|c|c|c|c|c|}
\hline \multirow[t]{2}{*}{ Treatment } & \multicolumn{6}{|c|}{ Egg quality } & \multirow[b]{2}{*}{$\operatorname{DEP}^{7}(\%)$} \\
\hline & $\mathrm{ESI}^{1}$ & $\mathrm{ESG}^{2}\left(\mathrm{~g} / \mathrm{cm}^{3}\right)$ & $\mathrm{ESS}^{3}\left(\mathrm{~kg} / \mathrm{cm}^{2}\right)$ & $\mathrm{HU}^{4}$ & $\mathrm{EST}^{5}(\mathrm{~mm})$ & CEP $^{6}(\%)$ & \\
\hline Local & 1.33 & 1.092 & $4.33 c$ & 79.59 & 0.37 & $1.01 \mathrm{~b}$ & $0.59 c$ \\
\hline $\mathrm{OVN}^{\circledR}$ & 1.34 & 1.089 & $4.06 \mathrm{~b}$ & 78.19 & 0.36 & $0.47 a$ & $0.27 a$ \\
\hline $\mathrm{NRC}+\mathrm{Hy} \cdot \mathrm{D}^{\circledR}$ & 1.34 & 1.090 & $4.07 b$ & 77.93 & 0.37 & $0.70 a b$ & $0.44 b$ \\
\hline NRC & 1.34 & 1.088 & $3.92 a$ & 78.91 & 0.36 & $1.46 c$ & $0.65 c$ \\
\hline SEM & 0.009 & 0.001 & 0.060 & 0.793 & 0.005 & 0.190 & 0.066 \\
\hline P-Value & 0.300 & 0.031 & $<0.001$ & 0.171 & 0.269 & $<0.001$ & $<0.001$ \\
\hline
\end{tabular}

a-c - Within a column, means with no common superscript letters are significantly different(p<0.05). 1 - Egg-shape index. 2 - Egg specific gravity. 3 - Eggshell strength. 4 - Haugh unit. 5 - Eggshell thickness. 6 - Cracked egg percent. 7 - Dirty egg percent. 
Table 4 - Effects of dietary treatment on the vitamin deposition in eggs of laying hens.

\begin{tabular}{|c|c|c|c|c|c|c|c|}
\hline \multirow{2}{*}{ Vitamins } & \multirow{2}{*}{ Unit } & \multicolumn{4}{|c|}{ Treatment } & \multirow[b]{2}{*}{ SEM } & \multirow[b]{2}{*}{ P-Value } \\
\hline & & Local & OVN $^{\circledR}$ & $\mathrm{NRC}+\mathrm{Hy} \cdot \mathrm{D}^{\circledR}$ & NRC & & \\
\hline Vitamin $B_{12}$ & $\mu \mathrm{g} / \mathrm{kg}$ & $4.81 a$ & $41.43 c$ & $18.10 \mathrm{~b}$ & $18.85 b$ & 1.03 & $<0.001$ \\
\hline Folic acid & $\mathrm{mg} / \mathrm{kg}$ & $4.34 b$ & $4.50 \mathrm{~b}$ & $2.53 a$ & $2.35 a$ & 0.14 & $<0.001$ \\
\hline Vitamin A & IU/kg & $25375.00 \mathrm{~b}$ & $31875.00 c$ & $20950.00 a$ & $22375.00 \mathrm{ab}$ & 1573.38 & $<0.001$ \\
\hline Vitamin $D_{3}$ & IU/kg & $1075.00 \mathrm{~b}$ & $1175.00 \mathrm{~b}$ & $0.00 \mathrm{a}$ & $0.00 \mathrm{a}$ & 85.39 & $<0.001$ \\
\hline $25-\mathrm{OH}-\mathrm{D}_{3}$ & $\mu \mathrm{g} / \mathrm{kg}$ & $26.33 b$ & $33.30 b c$ & $34.63 c$ & $12.82 \mathrm{a}$ & 3.36 & $<0.001$ \\
\hline Vitamin E & $\mathrm{mg} / \mathrm{kg}$ & $80.73 b$ & $112.75 c$ & $33.40 a$ & $32.75 a$ & 6.52 & $<0.001$ \\
\hline Vitamin $B_{1}$ & $\mathrm{mg} / \mathrm{kg}$ & $1.75 a$ & $2.40 \mathrm{~b}$ & $2.03 a$ & $1.88 a$ & 0.14 & 0.003 \\
\hline Vitamin $B_{2}$ & $\mathrm{mg} / \mathrm{kg}$ & 15.34 & 15.88 & 13.93 & 14.94 & 1.00 & 0.298 \\
\hline Vitamin $B_{6}$ & $\mathrm{mg} / \mathrm{kg}$ & LOD & LOD & LOD & LOD & & \\
\hline Vitamin $\mathrm{K}_{3}$ & $\mathrm{mg} / \mathrm{kg}$ & LOD & LOD & LOD & LOD & & \\
\hline Biotin & $\mu \mathrm{g} / \mathrm{kg}$ & $525.75 a$ & $871.50 \mathrm{~b}$ & $1115.00 \mathrm{c}$ & $1072.50 c$ & 56.97 & $<0.001$ \\
\hline Niacin & $\mathrm{mg} / \mathrm{kg}$ & $9.99 a$ & $13.33 a b$ & $18.85 c$ & $17.38 \mathrm{bc}$ & 2.20 & 0.007 \\
\hline Pantothenate & $\mathrm{mg} / \mathrm{kg}$ & $89.93 b$ & $98.53 c$ & $40.63 a$ & $41.78 a$ & 3.27 & $<0.001$ \\
\hline
\end{tabular}

LOD - Means below detection limit <LOD. a-c - Within a row, means with no common superscript letters are significantly different $(p<0.05)$.

significantly higher than for the NRC level $(p<0.05)$, but no significant difference was observed as compared with Local level or NRC level with Hy. ${ }^{\circledR}$. As for NRC level with Hy. ${ }^{\circledR}$ and NRC level, there was no significant difference for most of the vitamins, except for $25-\mathrm{OH}-\mathrm{D}_{3}$ concentrations, which improved in the NRC level with Hy. ${ }^{\circledR}$ group. Vitamin $B_{6}$ and vitamin $\mathrm{K}$ concentrations in eggs were not determined because they were below the detection limit.

\section{DISCUSSION}

As compared to the Local level, NRC level with Hy. ${ }^{\circledR}$ and NRC level, the fortified vitamins in the $O \mathrm{ON}^{\circledR}$ diet significantly decreased CEP and DEP. Hens receiving only NRC vitamins had an extremely high CEP and DEP, but this was reduced with the addition of Hy. ${ }^{\circledR}$. Furthermore, the ESS was significantly improved, suggesting the inability of regular vitamin $D$ to support maximal shell quality in eggs. The results of the present study were in accordance with the report of SotoSalanova \& Hernandez (2004) and Soto-Salanova \& Molinero (2005). It was clear that for NRC level with $H y . D^{\circledR}$ and NRC level, the only difference between them was Hy. ${ }^{\circledR}$ inclusion, and no other dietary difference. The $O \mathrm{OVN}^{\circledR}$ diet still contained vitamin $\mathrm{C}$ except for Hy. $D^{\circledR}$. Hy. ${ }^{\circledR}$ is a metabolite of vitamin $\mathrm{D}_{3}, 25-\mathrm{OH}-\mathrm{D}_{3}$ which is the most abundant circulating form of vitamin $D$ and plasma levels of the metabolite gives a good indication of the vitamin D status of the chick (Haussler \& Rasmussen, 1972). Positive effects of $25-\mathrm{OH}-\mathrm{D}_{3}$ on egg production and quality have been reported and summarized by Soares et al., (1995). Fritts \& Waldroup (2003) showed that at comparable levels of potency, 25-OH-D 3 was more efficacious than vitamin $D_{3}$ in terms of promoting bone and shell formation. Keshavarz (1996) reported that diets containing $6.25 \mu \mathrm{g}$ vitamin $D_{3} / \mathrm{kg}$ feed increased the incidence of cracked eggs and eggshell deformations. Poor shell quality is normally a result of poor calcium, phosphorus and vitamin D metabolism. Birds receiving $\mathrm{Hy} . \mathrm{D}^{\circledR}$ were able to maintain their plasma $25-\mathrm{OH}-\mathrm{D}_{3}$ at a higher level, thus helping to maintain their bone integrity, egg production and eggshell quality.

In addition to the observed changes in eggshell strength, vitamin $\mathrm{C}$ may play some role in improving bone properties and eggshell formation (Sergeev et al., 1990; Orban et al., 1993). Vitamin $C$ is required for the conversion of vitamin $D$ into its metabolite form calcitrol, which is essential for calcium regulation and the calcification process (Thornton, 1970). Vitamin C is an essential cofactor in the formation of collagen and of the extracellular matrix (Newman \& Leeson, 1997). This improvement may be attributed to increased calcium absorption, or possibly to the role that vitamin $C$ plays in the development of bone tissue.

Most reports about the effect of vitamin on egg quality focus on fat-soluble vitamins, while a few reports are on water-soluble vitamins, which also present different results. Keshavarz (2003) reported that supplementing vitamin $\mathrm{D}$ or $25-\mathrm{OH}-\mathrm{D}_{3}$ in the diet did not influence specific gravity of eggs from hens from 49 to 65 wk of age. Mattila et al. (2004) reported that no major differences in Haugh units, eggshell strength or specific gravity were observed between the control and vitamin $\mathrm{D}_{2}$ - or $\mathrm{D}_{3}$-enriched diets. On the other hand, Atencio et al. (2006) reported that eggs from hens fed the lowest vitamin $D_{3}$ levels had lower specific gravity than those from hens fed the highest vitamin $D_{3}$ levels. Mendonca et al. (2002) and Mori et al. (2003) reported 
that the eggshell index, specific gravity, shell thickness and albumen quality of eggs obtained from hens fed supplemental vitamin $A$ or vitamin $A$ and $E$ did not differ from those laid by hens fed the basal diet. Puth pongsiriporn et al. (2001) showed that dietary vitamin $E$ and $C$ supplementation had no significant effect on eggshell or Haugh units. Radwanet al. (2008) reported that the addition of vitamin E (100 or $200 \mathrm{mg} / \mathrm{kg}$ diet) in laying hens diets did not significantly affect eggshell thickness, egg shape index or Haugh units. Sahinet al. (2002), however, reported that egg specific gravity, eggshell thickness and Haugh unit were positively influenced by vitamin E supplementation in Japanese quails. Alteration of dietary vitamin level had minor effects on egg quality parameters in terms of the egg shape index, specific gravity, shell thickness and Haugh unit in the present study, which was in agreement with most of reports discussed above.

Vitamin concentration in the hen diet is the most important factor in determining vitamin content in the egg. As vitamin levels in the diet are increased, there is an increase in vitamin levels deposited in the albumen and/or yolk. Supplementation with increasing amounts of dietary vitamins for $\mathrm{OVN}^{\circledR}$ level produced significant improvement in egg vitamin concentrations in this present study, which is consistent with the report of Perez-Vendrellet al. (2003), who conducted a study in layers using fortified vitamin levels or those commonly used in Spain. For most of the vitamins there were increased accumulations in the egg in response to higher dietary supplementation. Some promising results have been highlighted by Leeson \& Caston (2003) for the potential transfer efficiency of some vitamins from hen diets to the egg. These authors studied the effect of supplementing the diet with two vitamin premixes (the regular level and enriched level), and results showed that the concentration of vitamin $B_{12}$ in enriched eggs significantly increased from 36 to over $100 \%$ DRI in response to an 11-fold increase in diet vitamin supplementation. There was also meaningful egg enrichment for vitamin $D_{3}$ and $E$, and the level of pantothenic acid was doubled, while vitamin $\mathrm{K}$ and biotin levels in modified eggs were not significantly different to those observed in regular eggs.

In the present study, Local level and OVN ${ }^{\circledR}$ level significantly improved the concentrations of vitamin $A$, vitamin $D_{3}$, vitamin $E$, folic acid and pantothenic acid in eggs as compared to NRC level with Hy. ${ }^{\circledR}$ and NRC level. Also the OVN ${ }^{\circledR}$ level produced significantly higher levels of vitamin A, E and pantothenic acid than the Local level. These results were in agreement with other investigators who reported the improvement of certain vitamin deposition in eggs when the hen diet was supplemented with a high dose of vitamin A (Squires \& Naber, 1993; Jiang et al., 1994; Surai et al., 1998), vitamin D3 ( Mattila et al., 1999; Mattila et al., 2003; Mattila et al., 2004), vitamin E (Frigg et al., 1992; Jiang et al., 1994; Qi \& Sim, 1998; Galobart et al., 2002; Grobas et al., 2002), folic acid (House et al., 2002; Hebert et al., 2005; Tactacan et al., 2010) or pantothenic acid (Leeson \& Caston, 2003). Mendonca et al., (2002) reported that progressive increases in the incorporation of retinol into egg yolk was verified when vitamin A was supplemented to the basal diet; egg yolk retinol content increased linearly as dietary vitamin A increased. Mori et al. (2003) reported yolk retinol concentration was enhanced by added vitamin A, from $24.6 \mathrm{lU} / \mathrm{g}$ for eggs from the control group, to 33.6 and $37.7 \mathrm{lU} / \mathrm{g}$ of yolk when hens were fed 15,000 and $30,000 \mathrm{lU} / \mathrm{kg}$ of diet. Yolk $\alpha$-tocopherol was significantly increased by dietary tocopherol supplementation, ranging from $10.9 \mathrm{\mu g} / \mathrm{g}$ (control group) to $160.6,264.1$, and $383.2 \mu \mathrm{g} / \mathrm{g}$ of yolk, respectively, when 200, 400 and $600 \mathrm{mg} / \mathrm{kg}$ of ration were added, respectively. Jiang et al. (1994) reported that egg yolk $\alpha$-tocopherol level linearly increased as dietary tocopherol increased. Pal et al. (2002) also showed that using 110 vs. $55 \mathrm{IU}$ vitamin E / kg diet doubled egg vitamin E content. Dickson et al. (2010) concluded that eggs of laying hens were consistently enriched with folate by the dietary supplementation with $4 \mathrm{mg}$ of folic acid $/ \mathrm{kg}$ of diet throughout the production cycle. Hoeyet al. (2009) and Bunchasak \& Kachana (2009) reported that it was possible to use synthetic folate at high doses (16 and $10 \mathrm{mg} / \mathrm{kg}$ diet) to produce novel eggs enriched with natural folates.

There was a significant increase in egg $25-\mathrm{OH}-\mathrm{D}_{3}$ concentration with the addition of Hy. $\mathrm{D}^{\circledR}$ to NRC level diet. This result was not consistent with Mattila et al. (1999), who reported a strong positive correlation between cholecalciferol content in poultry feed and cholecalciferol $(r=0.995)$ and 25 -hydroxycholecalciferol $(r=0.941)$ contents in egg yolk. Ovesen et al. (2003) also suggested that vitamin $D$ in eggs is present almost exclusively as 25-hydroxycholecalciferol, which is absorbed better and faster and has greater biological activity than cholecalciferol. Meanwhile, there was also a significant increase of in egg enrichment of vitamin $B_{1}$, vitamin $B_{12}$ and biotin in OVN ${ }^{\circledR}$ level, whereas the Local level did not produce any changes. Vitamin $B_{12}$ perhaps showed the best response, and this finding 
was in agreement with Squires \& Naber (1992), who reported that egg yolk vitamin $B_{12}$ concentration rapidly responded to dietary changes in the levels of this vitamin and was indicative of the vitamin $B_{12}$ status of the hen. Concentration of biotin in egg albumen increased with incremental dietary biotin levels, but egg yolk concentration was stable, and positive relationship between dietary biotin and the amount of biotin in eggs was also observed (Robel, 1991). The concentration of riboflavin in the eggs of hens fed the OVN ${ }^{\circledR}$ level and the Local level was higher than with the NRC level with Hy. ${ }^{\circledR}$ and NRC level, but no significant effect was observed. Naber \& Squires (1993) reported that there was nearly a linear relationship of diet riboflavin to egg riboflavin contents in the range of 1.5 to $5.0 \mathrm{mg} / \mathrm{kg}$ of feed. At 2 to 4 times the dietary requirement of the hens, riboflavin deposition in the eggs was limited by the transfer of riboflavin into the ovum (Squires \& Naber, 1993). Riboflavin deposition in the eggs was dependent on dietary riboflavin and reached half-maximal values at about $2 \mathrm{mg}$ of supplemental riboflavin (White et al., 1986).

Concentrations of vitamin $\mathrm{B}_{6}$ and vitamin $\mathrm{K}_{3}$ were not obtained because they were below the detection limit level in the present study. Considering its restricted biological role, very few studies have attempted to enhance its concentration in eggs. Suzuki \& Masayuki (1997) studying the increasing number of hemorrhagic diseases of newborn babies in relation to vitamin $\mathrm{K}$ deficiency of pregnant women, demonstrated that by feeding hens with high doses of either phylloquinone (vitamin $\mathrm{K}_{1}$ ), menaquinone (vitamin $\mathrm{K}_{2}$ ) or menadione (vitamin $K_{3}$ ), it was possible to increase the level of both $K_{1}$ and $K_{2}$ up to 1,908 and $240 \mu \mathrm{g} / 100 \mathrm{~g}$ egg yolk, respectively.

\section{CONCLUSION}

In conclusion, results of the present study demonstrated that hens receiving vitamins only at NRC levels presented an extremely high cracked egg and dirty egg rates, but this was reduced with the addition of Hy. ${ }^{\circledR}$. The addition of Hy. ${ }^{\circledR}$ significantly enhanced eggshell strength and $25-\mathrm{OH}-\mathrm{D}_{3}$ concentration in the egg. Hens receiving the Local vitamin levels produced more cracked eggs, dirty eggs and lower vitamin levels in eggs. Hens receiving OVN ${ }^{\circledR}$ vitamins produced eggs containing higher levels of most vitamins, with the least impact seen for dirty and cracked eggs. Apparently, proper vitamin nutrition has significant implications in gastrointestinal health of hens. This could have positive ramifications in marketing eggs with a higher vitamin level and a better nutritive value. The outcomes of this study will enable layer farmers to use vitamins more effectively for the development of functional eggs to meet the needs of specific individuals.

\section{REFERENCES}

Atencio A, Edwards HM Jr, Pesti GM, Ware GO. The vitamin $\mathrm{D}_{3}$ requirement of broiler breeders. Poultry Science 2006; 85(4):674-92.

Boushey CJ, Beresford SA, Omenn GS, Motulsky AG. A quantitative assessment of plasma homocysteine as a risk factor for vascular disease. Probable benefits of increasing folic acid intakes. The Journal of the American Medical Association 1995; 274(13):1049-57

Bunchasak C, Kachana S. Dietary folate and vitamin $B_{12}$ supplementation and consequent vitamin deposition in chicken eggs. Tropical Animal Health and Production 2009; 41(7):1583-1589.

Czeizel $A E$, Dudas I. Prevention of the first occurrence of neural-tube defects by periconceptional vitamin supplementation. The New England Journal of Medicine 1992; 327(26):1832-5.

Dickson TM, Tactacan GB, Hebert K, Guenter W, House JD. Optimization of folate deposition in eggs through dietary supplementation of folic acid over the entire production cycle of Hy-Line W36, Hy-Line W98, and CV20 laying hens. The Journal of Applied Poultry Research 2010; 19:80-91.

Eisen E, Bohren BB, McKean HE. The Haugh unit as a measure of egg albumen quality. Poultry Science 1962; 41:1461-1468.

Frigg M, Whitehead CC, Weber S. Absence of effects of dietary alpha -tocopherol on egg yolk pigmentation. British Poultry Science 1992; 33(2):347-353.

Fritts CA, Waldroup PW. Effect of Source and Level of Vitamin D on Live Performance and Bone Development in Growing Broilers. The Journal of Applied Poultry Research 2003; 12:45-52.

Galobart J, Barroeta AC, Cortinas L, Baucells MD, Codony R. Accumulation of alpha-tocopherol in eggs enriched with omega3 and omega6 polyunsaturated fatty acids. Poultry Science 2002; 81(12):1873-6.

Grobas S, Mendez J, Lopez BC, De BC, Mateos GG. Effect of vitamin E and A supplementation on egg yolk alpha-tocopherol concentration. Poultry Science $2002 ; 81(3): 376-381$.

Haussler MR, Rasmussen $\mathrm{H}$. The metabolism of vitamin $\mathrm{D}_{3}$ in the chick. The Journal of Biological Chemistry 1972; 247(8):2328-2335.

Hebert K, House JD, Guenter W. Effect of dietary folic acid supplementation on egg folate content and the performance and folate status of two strains of laying hens. Poultry Science 2005; 84(10):1533-1538.

Hempe JM, Lauxen RC, Savage JE. Rapid determination of egg weight and specific gravity using a computerized data collection system. Poultry Science $1988 ; 67(6): 902-7$

Hoey L, McNulty H, McCann EM, McCracken KJ, Scott JM, Marc BB, Molloy AM, Graham C, Pentieva K. Laying hens can convert high doses of folic acid added to the feed into natural folates in eggs providing a novel source of food folate. The British Journal of Nutrition 2009; 101(2):206-12.

House JD, Braun K, Balance DM, O'Connor CP, Guenter W. The enrichment of eggs with folic acid through supplementation of the laying hen diet. Poultry Science 2002; 81(9):1332-7 
Jiang YH, McGeachin RB, Bailey CA. alpha-tocopherol, beta-carotene, and retinol enrichment of chicken eggs. Poultry Science 1994; 73(7):1137-43.

Mendonca CX Jr, Almeida CRM, Mori AV, Watanabe C. Effect of Dietary Vitamin A on Egg Yolk Retinol and Tocopherol Levels. The Journal of Applied Poultry Research 2002; 11:373-378.

Keshavarz K. The effect of different levels of vitamin $C$ and cholecalciferol with adequate or marginal levels of dietary calcium on performance and eggshell quality of laying hens. Poultry Science 1996; 75(10):1227-35.

Keshavarz K. Comparison between cholecalciferol and 25-OHcholecalciferol on performance and eggshell quality of hens fed different levels of calcium and phosphorus. Poultry Science 2003; 82(9):1415-1422.

Leeson S, Caston LJ. Vitamin Enrichment of Eggs. The Journal of Applied Poultry Research 2003; 12:24-26.

Lips P, Duong T, Oleksik A, Black D, Cummings S, Cox D, Nickelsen T. A global study of vitamin D status and parathyroid function in postmenopausal women with osteoporosis: baseline data from the multiple outcomes of raloxifene evaluation clinical trial. The Journal of Clinical Endocrinology and Metabolism 2001; 86(3):1212-21

Mattila P, Valaja J, Rossow L, Venalainen E, Tupasela T. Effect of vitamin $D_{2}$ - and $D_{3}$-enriched diets on egg vitamin $D$ content, production, and bird condition during an entire production period. Poultry Science 2004; 83(3):433-40

Mattila $\mathrm{P}$, Lehikoinen $\mathrm{K}$, Kiiskinen $\mathrm{T}$, Piironen $\mathrm{V}$. Cholecalciferol and 25-hydroxycholecalciferol content of chicken egg yolk as affected by the cholecalciferol content of feed. Journal of Agricultural and Food Chemistry 1999; 47(10):4089-4092.

Mattila P, Rokka T, Konko K, Valaja J, Rossow L, Ryhanen EL. Effect of cholecalciferol-enriched hen feed on egg quality. Journal of Agricultural and Food Chemistry 2003; 51(1):283-287

McLean RR, Jacques PF, Selhub J, Tucker KL, Samelson EJ, Broe KE, Hannan MT, Cupples LA, Kiel DP. Homocysteine as a predictive factor for hip fracture in older persons. The New England Journal of Medicine 2004; 350:2042-2049.

Mori AV, Mendonca Jr CX, Almeida CRM, Pita MCG. Supplementing Hen Diets with Vitamins A and E Affects Egg Yolk Retinol and \{alpha\}-Tocopherol Levels. The Journal of Applied Poultry Research 2003; 12:106-114.

Morris MS. Homocysteine and Alzheimer's disease. The Lancet Neurology 2003; 2(7):425-428

Naber EC. Modifying Vitamin Composition of Eggs: A Review. The Journal of Applied Poultry Research 1993; 2:385-393.

Naber EC, Squires MW. Vitamin profiles of eggs as indicators of nutritional status in the laying hen: Diet to egg transfer and commercial flock survey. Poultry Science. 1993; 72:1046-1053.

Newman S, Leeson S. Skeletal integrity in layers at the completion of egg production. World's Poultry Science Journal 1997; 53:265-277.

Nys $Y$, Sauveur B. Valeur nutritionnelle des oeufs. INRA Productions Animales 2004; 17(5):385-393.

Orban Jl, Roland DA Sr, Cummins K, Lovell RT. Influence of large doses of ascorbic acid on performance, plasma calcium, bone characteristics, and eggshell quality in broilers and Leghorn hens. Poultry Science 1993; 72(4):691-700.

Ovesen L, Brot C, Jakobsen J. Food contents and biological activity of 25-hydroxyvitamin D: a vitamin D metabolite to be reckoned with? Annals of Nutrition and Metabolism 2003; 47(3-4):107-13.
Pal L, Dublecz K, Husveth F, Wagner L, Bartos A, Kovacs G. Effect of dietary fats and vitamin $E$ on fatty acid composition, vitamin $A$ and $E$ content and oxidative stability of egg yolk. Archiv fur Geflugelkunde 2002; 66(6):251257

Perez-Vendrell AM, Hernandez JM, Llaurado LL, Brufau J. Improving the nutritive value of eggs by feeding laying hens an optimum vitamin nutrition (OVNTM). Proceedings of the 16th European Symposium on Quality of Poultry Meat; 2003; SaintBrieux. France. p. 23-26.

Puthpongsiriporn U, Scheideler SE, Sell JL, Beck MM. Effects of vitamin E and $C$ supplementation on performance, in vitro lymphocyte proliferation, and antioxidant status of laying hens during heat stress. Poultry Science 2001; 80(8):1190-1200

Qi GH, Sim JS. Natural tocopherol enrichment and its effect in n-3 fatty acid modified chicken eggs. Journal of Agricultural and Food Chemistry. 1998; 46(5):1920-1926

Radhika MS, Bhaskaram P, Balakrishna N, Ramalakshmi BA, Devi S, Kumar BS. Effects of vitamin A deficiency during pregnancy on maternal and child health. BJOG: An International Journal of Obstetrics and Gynaecology 2002; 109(6):689-93

Radwan NL, Hassan RA, Qota EM, Fayek HM. Effect of natural antioxidant on oxidative stability of eggs and productive and reproductive performance of laying hens. International Journal of Poultry Science 2008; 7(2):134-150.

Refsum H, Ueland PM, Nygard O, Vollset SE. Homocysteine and cardiovascular disease. Annual Review of Medicine 1998; 49:31-62.

Robel EJ. The value of supplemental biotin for increasing hatchability of turkey eggs. Poultry Science 1991; 70(8):1716-22.

Sahin K, Sahin N, Onderci M. Vitamin E supplementation can alleviate negative effects of heat stress on egg production, egg quality, digestibility of nutrients and egg yolk mineral concentrations of Japanese quails. Research in Veterinary Science 2002; 73(3):307-12

Scharla SH. Prevalence of subclinical vitamin D deficiency in different European countries. Osteoporosis International 1998; 8 Suppl 2:S7-12.

Scott JM. Folate and vitamin B12. Proceeding of the Nutrition Society 1999 $58(2): 441-8$

Sergeev IN, Arkhapchev YP, Spirichev VB. Ascorbic acid effects on vitamin D hormone metabolism and binding in guinea pigs. The Journal of Nutrition 1990; 120(10):1185-90

Soares Jr JJ, Kerr JM, Gray RW. 25-hydroxycholecalciferol in poultry nutrition. Poultry Science 1995; 74(12):1919-34

Soto-Salanova MF, Molinero A. Efficacy of the use of Hy.D ${ }^{\circledR}$ in laying hens Proceedings of the $11^{\text {th }}$ European Symposium on the Quality of Eggs and Egg Products; 2005; Doorwerth. Netherlands; 2005. p. 23-26.

Soto-Salanova MF, Hernandez JM. Practical study on the effect of feeding Optimum Vitamin Nutrition and 25-hydroxycholecalciferol on production and egg quality of layers. Proceedings of the 22th World's Poultry Congress; 2004; Istanbul. Turkey; 2004. p. 8-13.

Squires MW, Naber EC. Vitamin profiles of eggs as indicators of nutritional status in the laying hen: vitamin $B_{12}$ study. Poultry Science 1992; 71(12): 2075-82.

Squires MW, Naber EC. Vitamin profiles of eggs as indicators of nutritional status in the laying hen: riboflavin study. Poultry Science 1993; 72(3):48394

Squires MW, Naber EC. Vitamin profiles of eggs as indicators of nutritional 
status in the laying hen: vitamin A study. Poultry Science 1993; 72(1):15464.

Surai PF, lonov IA, Kuklenko TV, Kostjuk IA, MacPherson A, Speake BK, Noble RC, Sparks NH. Effect of supplementing the hen's diet with vitamin $A$ on the accumulation of vitamins $A$ and $E$, ascorbic acid and carotenoids in the egg yolk and in the embryonic liver. British Poultry Science 1998; 39(2):257-63.

Suzuki Y, Masayuki O. Production of hen's eggs rich in vitamin K. Nutrition Research 1997; 17(10):1607-1615.

Tactacan GB, Jing M, Thiessen S, Rodriguez-Lecompte JC, O'Connor DL, Guenter W, House JD. Characterization of folate-dependent enzymes and indices of folate status in laying hens supplemented with folic acid or 5-methyltetrahydrofolate. Poultry Science 2010; 89:688-696.

Thornton PA. Influence of exogenous ascorbic acid on calcium and phosphorus metabolism in the chick. The Journal of Nutrition 1970; 100(12):1479-85.

Tuohimaa P, Lyakhovich A, Aksenov N, Pennanen $P$, Syvala $H$, Lou YR, Ahonen $M$, Hasan T, Pasanen P, Blauer M, Manninen T, Miettinen $S$, Vilja $P$, Ylikomi T. Vitamin D and prostate cancer. The Journal of Steroid Biochemistry and Molecular Biology 2001; 76(1-5):125-134.

Underwood BA. Perspectives from micronutrient malnutrition elimination/ eradication programmes. Bulletin of the World Health Organization 1998; 76 Suppl 2:34-7.

White HR, Armstrong J, Whitehead CC. Riboflavin-binding protein. Concentration and fractional saturation in chicken eggs as a function of dietary riboflavin. Biochemical Journal 1986; 238(3):671-675. 